\title{
COMMENTARY
}

\section{Liberation and animation for ventilated ICU patients: the ABCDE bundle for the back-end of critical care}

\author{
Pratik Pandharipande ${ }^{1,2 *}$, Arna Banerjee 2 , Stuart McGrane ${ }^{2}$ and E Wesley Ely ${ }^{3}$ \\ See related research by Jackson et al., http://ccforum.com/content/14/2/R59
}

\begin{abstract}
Critically ill patients are frequently prescribed sedatives and analgesics to ensure patient safety, to relieve pain and anxiety, to reduce stress and oxygen consumption, and to prevent patient ventilator dysynchrony.

Recent studies have revealed that these medications themselves contribute to worsening clinical outcomes. An evidence-based organizational approach referred to as the $A B C D E$ bundle (Awakening and Breathing Coordination of daily sedation and ventilator removal trials; Choice of sedative or analgesic exposure; Delirium monitoring and management; and Early mobility and Exercise) is presented in this commentary.
\end{abstract}

In the previous issue of Critical Care, Jackson and colleagues performed a systematic literature review with the goal of evaluating the impact of sedation practices on the safety and economic outcomes in intensive care unit (ICU) patients [1]. Heterogeneity of the different patient populations studied and variations in methodology prevented the authors from conducting a formal quantitative data synthesis and analysis; hence their article is primarily a collation of published studies. The authors conclude that the past decade has seen much focus on sedation practices during critical illness and that a systematic approach to sedation and analgesia improves patient outcomes. Using the review as a springboard for our commentary, we would like to focus the reader towards an evidence-based paradigm for improving the quality of care and clinical outcomes of ventilated patients.

${ }^{*}$ Correspondence: Pratik.pandharipande@vanderbilt.edu

'Anesthesiology Service, VA TN Valley Health Care System, 1310 24th Ave South,

Nashville 37212, USA

Full list of author information is available at the end of the article
Over the past 15 years, we have learned in critical care that there are many potentially life-saving maneuvers we perform at the outset of a patient's illness (for example, source control of infections, antibiotics, aggressive resuscitation); we will refer to this as the front-end of critical care. It is now becoming imperative for us to improve our management of the back-end of critical care in order to optimize patients' recovery and outcomes. We must therefore begin to focus on strategies to liberate our patients from life support that was instituted during the front-end period of high illness severity and then animate (get them out of the bed earlier) by focusing on five evidence-based steps of care. We refer to these steps as the $\mathrm{ABCDE}$ bundle (Awakening and Breathing Coordination of daily sedation and ventilator removal trials; Choice of sedative or analgesic exposure; Delirium monitoring and management; and Early mobility and Exercise).

Critically ill patients are frequently prescribed sedatives and analgesics - especially if they are on mechanical ventilation $(\mathrm{MV})$ - to ensure patient safety, to relieve pain and anxiety, to reduce stress and oxygen consumption, and to prevent patient ventilator dysynchrony. Scientific advances in the past 10 to 15 years have revealed that these medications themselves contribute to increased morbidity, and perhaps even mortality [2-4]. Additionally a solid body of evidence demonstrates an independent association between commonly prescribed benzodiazepines and their attendant risk of delirium [2], and likewise the relationship between delirium and a dementia-like brain dysfunction following ICU care and mortality [5-7]. These observations have literally forced healthcare providers to study and determine best sedation practices to liberate patients faster from MV.

To fully understand ventilator liberation, one needs to review what happened to weaning during the 1990s. First, protocolization and daily spontaneous breathing trials were proven superior to the ongoing varied approaches to ventilator weaning [8]. This was vitally important because of documentation showing that about 
two-thirds of the time on MV was spent during weaning, so anything that reduced this period would have a very high likelihood of improving outcomes. By the late 1990s and early 2000s, another body of literature was growing that showed continuous sedative infusions were associated with worse clinical outcomes and that protocolized, target-based sedation, with the incorporation of daily awaking trials (daily sedation cessation), resulted in decreased sedative exposure and shorter times on the ventilator [3,9].

The next advance was bringing these two areas of weaning together for formal testing. The Awakening and Breathing Controlled trial combined spontaneous awakening trials with spontaneous breathing trials (the ABCs of liberation from MV) and yielded a 4-day reduction in ICU and hospital lengths of stay and an unprecedented $15 \%$ reduction in 1-year mortality [4]. This study pointed to the importance of removing the silos of our care paradigms by centering the care delivered by nurses and respiratory therapists in an interdigitating protocol with checks and balances to improve patient safety and quality.

Liberation from MV is often hampered by nonpulmonary organ dysfunction. In a subgroup analysis of the ARDSnet low versus high tidal volume study, it was noted that older survivors recovered from respiratory failure and achieved spontaneous breathing at the same rate as younger patients, but had greater difficulty achieving liberation from the ventilator and successful ICU discharge [10]. This study led to the hypothesis that older patients developed acute brain dysfunction (manifested as delirium and coma); but without validated tools to diagnose this dysfunction in the ICU, the hypothesis could not be tested.

Development of easy to use delirium monitoring instruments such as the Confusion Assessment Method for the ICU [11] and the Intensive Care Delirium Screening Checklist [12] (the D of the ABCDEs) led to investigations that quantified the undesirable consequences of delirium in the critically ill [5-7], and identified sedative medications (benzodiazepines in particular) as modifiable risk factors for delirium [2]. Psychoactive medications could for the first time be compared using central nervous system outcomes (delirium). The ensuing MENDS and SEDCOM studies compared benzodiazepines $\left(\mathrm{GABA}_{\mathrm{A}}\right.$ agonists) versus dexmedetomidine (an $\alpha_{2}$-agonist) and showed that patients managed with the $\alpha_{2}$-agonist approach experienced a $20 \%$ or more reduction in the daily rates of delirium while on MV [13-15].

The ability to monitor for delirium has also allowed us an opportunity to study analgosedation techniques that focus on treating pain first and on utilizing the sedating properties of the analgesics, thus avoiding GABA $_{A^{-}}$ agonists. Such techniques have been associated with shorter times on MV and in the ICU [16], and may reduce the overall burden of delirium and its consequences, given that pain itself predisposes patients to delirium. Clearly much works needs to be done in this area, as we determine best strategies to prevent and manage delirium.

The last component of the ABCDE bundle is related to the need for early mobility and exercise (the $E$ of the ABCDEs) to prevent and rehabilitate the muscles and nerves of the body experiencing the nearly universal problem of ICU-acquired weakness. Surely immobilization and comatose states associated with heavy sedation and $\mathrm{MV}$ are contributors, yet some degree of this acquired disease process develops even without sedation and MV. It was only recently that Schweickert and colleagues incorporated an early physical therapy program in addition to daily sedation cessations, and demonstrated that patients who underwent early mobilization had a significant improvement in functional status at hospital discharge [17]. This study also showed that the early mobility group experienced roughly a $50 \%$ reduction in the duration of delirium in the ICU and hospital [17], supporting interconnectedness of the brain and body via the mantra that 'exercise sparks the brain'.

Healthcare providers are thus encouraged to incorporate strategies that lead to early liberation and animation; the ABCDE bundle represents just one method of approaching the organizational changes that need to occur to effect a change of culture that will breed success. Persisting with our old approach to the back-end of care for these vulnerable patients is possible, but it is irresponsible in light of the growing body of evidence that says we can do so much better for our patients. Given that there are negligible adverse consequences of implementing these recommended strategies $[4,9,17]$, minimal costs associated with changing commonly prescribed medications $[14,18]$, and no evidence of adverse short or long-term psychiatric or neuropsychological effects of minimizing sedation exposure $[19,20]$, the pendulum needs to swing back to having interactive patients with well-controlled pain who can participate in physical and cognitive activities at the earliest possible safe point in their critical illness.

\section{Abbreviations}

ICU, intensive care unit; MV, mechanical ventilation.

\section{Acknowledgements}

PP is the recipient of the VA Clinical Science Research and Development Service Award (VA Career Development Award) and the ASCCA-FAER-Abbott Physician Scientist Award. EWE is supported by the VA Clinical Science Research and Development Service (VA Merit Review Award) and by a grant from the National Institutes of Health (AG0727201).

\section{Competing interests}

PP has received research grants from Hospira Inc. and honoraria from GSK and Hospira Inc. EWE has received research grants and honoraria from Hospira Inc., Pfizer, and Eli Lilly, and a research grant from Aspect Medical Systems. The other authors report no financial disclosures. 


\section{Author details}

'Anesthesiology Service, VA TN Valley Health Care System, 1310 24th Ave South, Nashville 37212, USA. ${ }^{2}$ Department of Anesthesiology, Division of Critical Care, Vanderbilt University Medical Center, 526 MAB, 121121 st Ave South, Nashville, TN 37027, USA. ${ }^{3}$ Department of Medicine, Division of Pulmonary Critical Care, Vanderbilt University Medical Center and the VA TN Valley GRECC, 6000 HSR, 1211 21st Ave South, Nashville, TN 37027, USA.

Published: 20 May 2010

\section{References}

1. Jackson D, Proudfoot C, Cann CF, Walsh T: A systematic review of the impact of sedation practice in the ICU on resource use, costs and patient safety. Crit Care 2010, 14:R59.

2. Pandharipande P, Shintani A, Peterson J, Pun BT, Wilkinson GR, Dittus RS Bernard GR, Ely EW: Lorazepam is an independent risk factor for transitioning to delirium in intensive care unit patients. Anesthesiology 2006, 104:21-26.

3. Kollef MH, Levy NT, Ahrens TS, Schaiff R, Prentice D, Sherman G: The use of continuous i.v. sedation is associated with prolongation of mechanical ventilation. Chest 1998, 114:541-548.

4. Girard TD, Kress JP, Fuchs BD, Thomason JW, Schweickert WD, Pun BT, Taichman DB, Dunn JG, Pohlman AS, Kinniry PA, Jackson JC, Canonico AE, Light RW, Shintani AK, Thompson JL, Gordon SM, Hall JB, Dittus RS, Bernard GR, Ely EW: Efficacy and safety of a paired sedation and ventilator weaning protocol for mechanically ventilated patients in intensive care (Awakening and Breathing Controlled trial): a randomised controlled trial. Lancet 2008, 371:126-134.

5. Pisani MA, Kong SY, KasI SV, Murphy TE, Araujo KL, Van Ness PH: Days of delirium are associated with 1-year mortality in an older intensive care unit population. Am J Respir Crit Care Med 2009, 180:1092-1097.

6. Jackson JC, Gordon SM, Hart RP, Hopkins RO, Ely EW: The association between delirium and cognitive decline: a review of the empirical literature. Neuropsychol Rev 2004, 14:87-98.

7. Ely EW, Shintani A, Truman B, Speroff T, Gordon SM, Harrell FE, Jr., Inouye SK, Bernard GR, Dittus RS: Delirium as a predictor of mortality in mechanically ventilated patients in the intensive care unit. JAMA 2004, 291:1753-1762.

8. Ely EW, Baker AM, Dunagan DP, Burke HL, Smith AC, Kelly PT, Johnson MM, Browder RW, Bowton DL, Haponik EF: Effect on the duration of mechanical ventilation of identifying patients capable of breathing spontaneously. N Engl J Med 1996, 335:1864-1869

9. Kress JP, Pohlman AS, O'Connor MF, Hall JB: Daily interruption of sedative infusions in critically ill patients undergoing mechanical ventilation. NEngl J Med 2000, 342:1471-1477.

10. Ely EW, Wheeler AP, Thompson BT, Ancukiewicz M, Steinberg KP, Bernard GR: Recovery rate and prognosis in older persons who develop acute lung injury and the acute respiratory distress syndrome. Ann Intern Med 2002, 136:25-36.
11. Ely EW, Inouye SK, Bernard GR, Gordon S, Francis J, May L, Truman B, Speroff T, Gautam S, Margolin R, Hart RP, Dittus R: Delirium in mechanically ventilated patients: validity and reliability of the confusion assessment method for the intensive care unit (CAM-ICU). JAMA 2001, 286:2703-2710.

12. Bergeron N, Dubois MJ, Dumont M, Dial S, Skrobik Y: Intensive Care Delirium Screening Checklist: evaluation of a new screening tool. Intensive Care Med 2001, 27:859-864.

13. Riker RR, Shehabi Y, Bokesch PM, Ceraso D, Wisemandle W, Koura F, Whitten $P$, Margolis BD, Byrne DW, Ely EW, et al:: Dexmedetomidine vs midazolam for sedation of critically ill patients: a randomized trial. JAMA 2009, 301:489-499.

14. Pandharipande PP, Pun BT, Herr DL, Maze M, Girard TD, Miller RR, Shintani AK, Thompson JL, Jackson JC, Deppen SA, Stiles RA, Dittus RS, Bernard GR, Ely EW: Effect of sedation with dexmedetomidine vs lorazepam on acute brain dysfunction in mechanically ventilated patients: the MENDS randomized controlled trial. JAMA 2007, 298:2644-2653.

15. Pandharipande PP, Sanders RD, Girard TD, McGrane S, Thompson JL, Shintani AK, Herr DL, Maze M, Ely EW: Effect of dexmedetomidine versus lorazepam on outcome in patients with sepsis: an a priori-designed analysis of the MENDS randomized controlled trial. Crit Care 2010, 14:R38.

16. Strom T, Martinussen T, Toft P: A protocol of no sedation for critically ill patients receiving mechanical ventilation: a randomised trial. Lancet 2010 375:475-480.

17. Schweickert WD, Pohlman MC, Pohlman AS, Nigos C, Pawlik AJ, Esbrook CL, Spears L, Miller M, Franczyk M, Deprizio D, Schmidt GA, Bowman A, Barr R, McCallister KE, Hall JB, Kress JP: Early physical and occupational therapy in mechanically ventilated, critically ill patients: a randomised controlled trial. Lancet 2009, 373:1874-1882.

18. Dasta JF, Kane-Gill SL, Pencina M, Shehabi Y, Bokesch PM, Wisemandle W, Riker RR: A cost-minimization analysis of dexmedetomidine compared with midazolam for long-term sedation in the intensive care unit. Crit Care Med 2010, 38:497-503.

19. Jackson JC, Girard TD, Gordon SM, Thompson JL, Shintani AK, Thomason JW, Pun BT, Canonico AE, Dunn JG, Bernard GR, Dittus RS, Ely EW: Long-term cognitive and psychological outcomes in the Awakening and Breathing Controlled trial. Am J Respir Crit Care Med 2010. [Epub ahead of print]

20. Kress JP, Gehlbach B, Lacy M, Pliskin N, Pohlman AS, Hall JB: The long-term psychological effects of daily sedative interruption on critically ill patients. Am J Respir Crit Care Med 2003, 168:1457-1461.

doi:10.1186/cc8999

Cite this article as: Pandharipande $P$, et al: Liberation and animation for ventilated ICU patients: the ABCDE bundle for the back-end of critical care. Critical Care 2010, 14:157. 